\title{
UNMODIFIED AND GOLD-MODIFIED SEMICONDUCTOR CATALYSTS FOR SOLAR LIGHT ASSISTED PHOTODEGRADATION OF CRYSTAL VIOLET
}

\author{
ZSIGMOND PAPPa*
}

\begin{abstract}
Different unmodified and modified semiconductor photocatalysts were used for the complete decolorization of an unbuffered crystal violet solution. The decolorization efficiency of commercially available $\mathrm{ZnO}$ and $\mathrm{TiO}_{2}$ (anatase nanopowder) was compared with those of newly prepared goldmodified $\mathrm{ZnOs}$ (Au/ZnOs). Two Au/ZnOs were prepared from pure $\mathrm{ZnO}$ powder through deposition of gold by direct current (DC) sputtering. The morphological characterization of the Au/ZnOs was done with the aid of scanning electron microscopy. ZnO-based catalysts show significantly higher decolorization power in comparison with $\mathrm{TiO}_{2}$. $\mathrm{Au} / \mathrm{ZnO}$ s show slightly higher activity than unmodified $\mathrm{ZnO}$.
\end{abstract}

Keywords: semiconductor oxides, modification with gold, sputter coating, photodegradation, crystal violet

\section{INTRODUCTION}

Effluents of various industries usually contain high quantities of synthetic organic dyes. The discharge of these colored compounds in the environment causes considerable non-aesthetic pollution and serious healthrisk factors. Since dyes usually show high stability under sunlight and resistance to microbial attack and temperature, the large majority of these compounds are not degradable in conventional wastewater treatment plants. The research of powerful and practical treatments to decolorize and degrade dyeing wastewaters to decrease their environmental impact has then attracted increasing interest over the past two decades. Physico-chemical, chemical and electrochemical methods, advanced oxidation processes (AOPs), microbiological treatments, and enzymatic decomposition are the most important among these technologies [1].

\footnotetext{
a Faculty of Biofarming, John Naisbitt University, Maršala Tita 39, 24300 Bačka Topola, Serbia, e-mail: pappzsigmond@yahoo.com, zpap@naisbitt.edu.rs
} 
AOPs, which involve the in-situ generation of highly potent chemical oxidants such as the hydroxyl radical, have emerged as an important avenue of technologies to accelerate the non-selective oxidation and thus the destruction of a wide range of non-degradable organic contaminants in wastewater which cannot be eliminated biologically [2, 3].

Recently, the application of metal oxide semiconductors in the AOPs has gained wide interest for the treatment of dye wastewater owing to its good degradation efficiency, low toxicity and physical and chemical properties [2]. On the other hand, photocatalytic efficiency of semiconductor particles is often limited by the quick recombination of the photogenerated charge carriers $[4,5]$. One of the mostly used ways to overcome these limitations is deposition of noble metals on the semiconductor surface, which prevents the recombination of the electron-hole pairs and consequently increases its photocatalytic activity [6-8]. Noble metal-modified $\mathrm{ZnOs}$ are nowadays broadly applied in photocatalytic degradation of different dyes [9-30]. These catalysts are practically always synthesized in solution using a large variety of different synthetic procedures. Only few examples are presented about the use of sputtering technique for obtaining such catalysts for the degradation of organic dyes [18, 20]. To best of my knowledge there are no publications dealing with gold-modified $\mathrm{ZnOs}$ obtained by sputtering technique for the photocatalytic degradation of crystal violet dye (Fig. 1).

In this work two gold-modified $\mathrm{ZnO}$ photocatalysts (Au/ZnOs) were prepared by direct current (DC) sputtering and their decolorization efficiency was compared with those of commercially available $\mathrm{ZnO}$ and $\mathrm{TiO}_{2}$ (anatase nanopowder). Scanning electron microscopy/energy dispersive spectrometry (SEM / EDS) was applied for morphological, structural and elemental characterization of the modified catalysts.

\section{RESULTS AND DISCUSSION}

The decolorization efficiency of unmodified $\mathrm{ZnO}$ and $\mathrm{TiO}_{2}$ was compared to those of $A u / Z n O s$ under direct and diffuse natural solar irradiation (in further text $\mathrm{Au} / \mathrm{ZnO} / 1$ and $\mathrm{Au} / \mathrm{ZnO} / 2$ denote $\mathrm{Au} / \mathrm{ZnO}$ samples with lower and higher gold content, respectively; see Experimental section for details). The photolytic degradation was also monitored under the same conditions. Generally, the efficiency of $\mathrm{ZnO}$-based catalysts was undoubtedly higher in comparison with $\mathrm{TiO}_{2}$ under both irradiation types (Fig. 2A, B; bars 2-5). Although $\mathrm{ZnO}$ showed quite high activity, both newly synthesized gold-modified catalysts surpassed its efficiency (Fig. 2A, B; bars 2-4). 
The relative difference between $\mathrm{ZnO}$-based catalysts was more pronounced under direct irradiation (Fig. 2A; bars 2-4). While the relative difference between $\mathrm{Au} / \mathrm{ZnO} / 2$ and $\mathrm{ZnO}$ was around $14 \%$ under direct irradiation (Fig. 2A; bars 2, 4), this difference was just around $5 \%$ in case of diffuse sunlight (Fig. 2B; bars 2, 4). Similar conclusion is valid for the comparison of $\mathrm{TiO}_{2}$ and $\mathrm{ZnO}$-based catalytic systems (both unmodified and modified). While the decolorization time is 9.5-11.1 times higher under direct irradiation (Fig. 2A; bars 2-5), it is just 6.1-6.4 times higher in case of diffuse sunlight (Fig. 2B; bars 2-5).

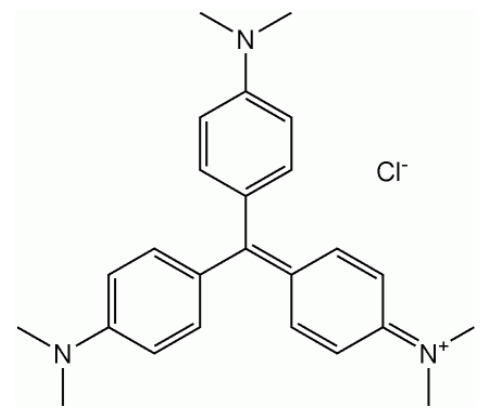

Figure 1. Structural formula of crystal violet.

The photolytic degradation was incomparably slower to catalytic ones in both cases (Fig. 2A, B; bars 1-5). The decolorization time under diffuse irradiation is significantly higher than under direct sunlight for all investigated systems (56.3× for photolysis, $23.1 \times$ for $\mathrm{TiO}_{2}, 36.1 \times$ for $\mathrm{ZnO}, 38.2 \times$ for $\mathrm{Au} / \mathrm{ZnO} / 1,40.0 \times$ for $\mathrm{Au} / \mathrm{ZnO} / 2)$.
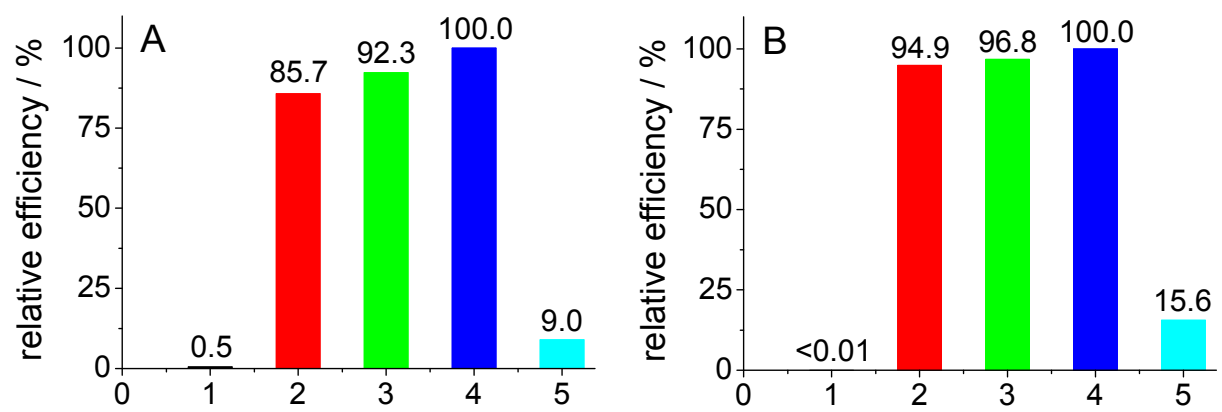

Figure 2. Comparison of the efficiency of different procedures of crystal violet photodegradation under direct $(A)$ and diffuse solar irradiation (B): photolysis (1), $\mathrm{ZnO}$ (2), Au/ZnO/1 (3), Au/ZnO/2 (4), $\mathrm{TiO}_{2}$ (5); Ccatalyst (2-5) = $2.00 \mathrm{~g} \mathrm{dm}^{-3}$. 
The optimal catalyst concentration for the most efficient catalytic system (Au/ZnO/2) was determined in a separate experiment (Fig. 3). It was found that the decolorization time was the shortest at $2.00 \mathrm{~g} \mathrm{dm}^{-3}$ concentration. Both lower and higher catalyst amounts resulted in slower decolorization. The reason of lowered efficiency above the optimum concentration could be explained by particle aggregation, decreased light penetration and increased light scattering.

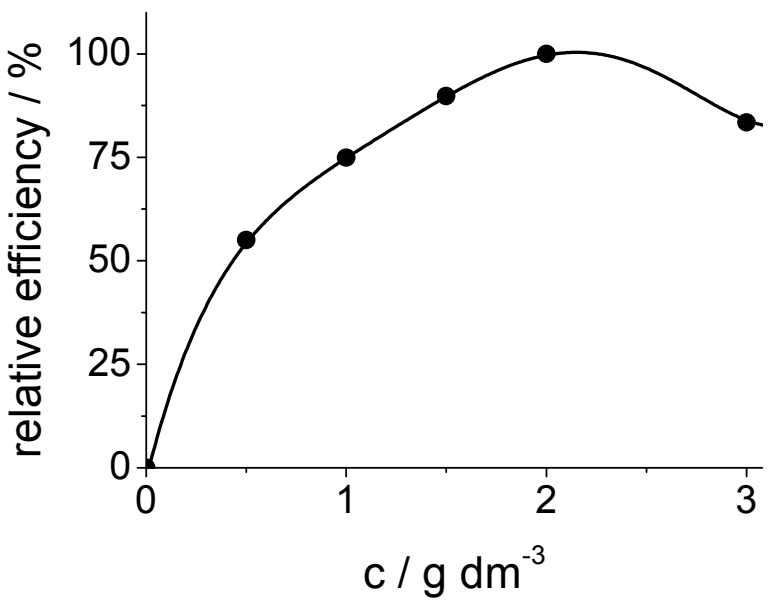

Figure 3. Effect of Au/ZnO/2 concentration on decolorization efficiency.

Under the optimal Au/ZnO/2 concentration $\left(2.00 \mathrm{~g} \mathrm{dm}^{-3}\right)$, full decolorization of crystal violet was achieved in less than 7 minutes under direct solar irradiation (Fig. 4). The decolorization kinetics was monitored spectrophotometrically. The signal decreased linearly with time at all investigated absorption maxima both in UV (302 and $249 \mathrm{~nm}$ ) and visible range $(590 \mathrm{~nm})$, indicating zero-order kinetics. The reaction rate constant was $3.06 \times 10^{-8}$ $(590 \mathrm{~nm}), 2.97 \times 10^{-8}(302 \mathrm{~nm})$, and $3.08 \times 10^{-8} \mathrm{~mol} \mathrm{dm}^{-3} \mathrm{~s}^{-1}(249 \mathrm{~nm})$, showing very similar behavior at all maxima. It was also clear that adsorption of crystal violet occured before the photodegradation process ( $20 \%$ in 15 minutes without irradiation; Fig. 4A, upper two spectra). 

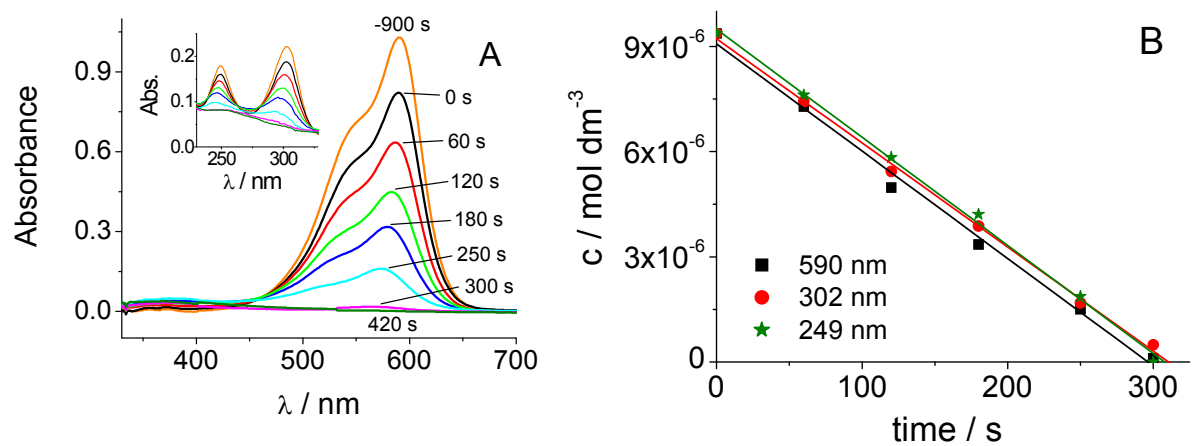

Figure 4. Spectrophotometric monitoring of crystal violet decolorization over $\mathrm{Au} / \mathrm{ZnO} / 2(\mathrm{~A})$ together with corresponding kinetic curves (B). Upper two spectra (A) correspond to the adsorption process in dark before the kinetic experiment.

$\mathrm{Au} / \mathrm{ZnO} / 2$ catalyst was also subjected to a physicochemical investigation. Typical micrographs taken under different magnifications (Fig. 5A, B) show its morphological characteristics. Agglomerates consisted from smaller particles with the size mostly in $80-500 \mathrm{~nm}$ range are clearly visible. Separate gold particles with size comparable to the size of $\mathrm{ZnO}$ particles were not identified in the sample.
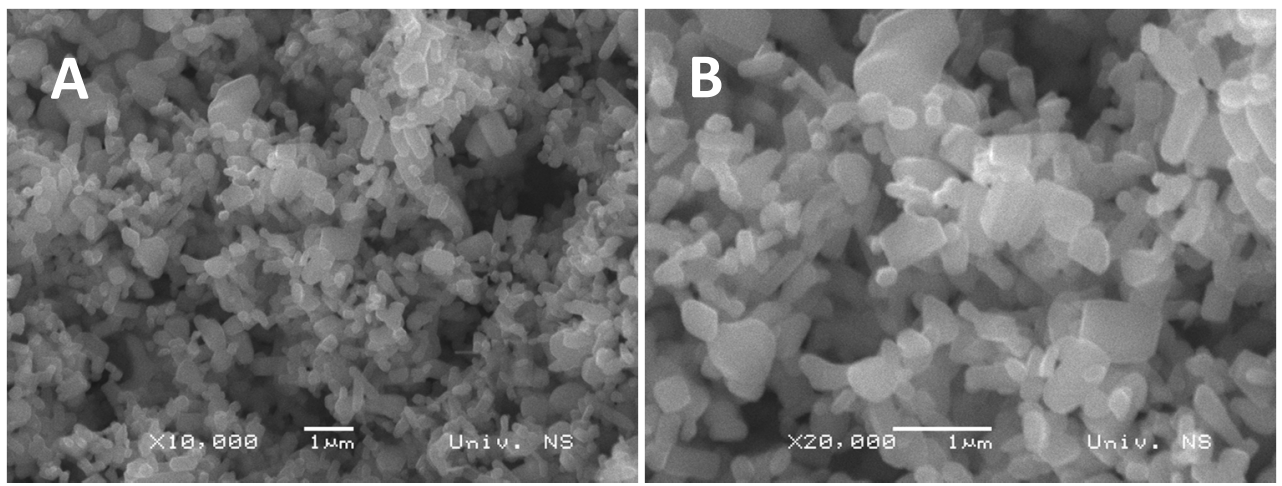

Figure 5. SEM micrographs of the $\mathrm{Au} / \mathrm{ZnO} / 2$ sample under different magifications $(\times 10,000(A), \times 20,000(B))$.

The EDS analysis of the catalyst showed the expected ratio of zinc and oxygen for pure $\mathrm{ZnO}$, while the concentration of Au was under $0.35 \%(\mathrm{w} / \mathrm{w})$. The presence of other elements was negligible. 


\section{CONCLUSIONS}

New gold-modified zinc oxides (Au/ZnOs) have been prepared from pure $\mathrm{ZnO}$ by $\mathrm{DC}$ sputtering technique and successfully applied in solar photodegradation of crystal violet dye. These modified catalysts were compared with unmodified $\mathrm{ZnO}$ and $\mathrm{TiO}_{2}$. $\mathrm{ZnO}$-based catalysts were significantly more efficient in comparison with $\mathrm{TiO}_{2}$ (anatase nanopowder). The presence of gold slightly enchanced the efficiency of pure $\mathrm{ZnO}$. The differences in the catalytic activities of the investigated catalysts were more pronounced in the case of direct solar irradiation. As expected, the degradation was undoubtedly faster under direct than diffuse sunlight. The most efficient from the investigated catalysts $(\mathrm{Au} / \mathrm{ZnO} / 2)$ was morphologically characterized using SEM. The optimal concentration of Au/ZnO/2 was also determined $\left(2.00 \mathrm{~g} \mathrm{dm}^{-3}\right)$. Degradation of crystal violet over this catalyst showed zero-order kinetics.

It must be stated that from the economic point of view (economicity vs. effectiveness), higher catalytic efficiency achieved with gold modification is not sufficiently justified, especially because of excellent activity of unmodified $\mathrm{ZnO}$. In any case, this contribution broadens the field of preparation and application of noble metal-modified semiconductor catalysts for solar photodegradation of organic pollutants.

\section{EXPERIMENTAL SECTION}

\section{Chemicals and solutions}

Solution of crystal violet (Merck) was prepared by dissolving the dye in double distilled water $\left(\mathrm{c}_{0}=1.18 \times 10^{-5} \mathrm{~mol} \mathrm{dm}^{-3}\right.$; Abso $\left.(590 \mathrm{~nm})=1.02\right)$. $\mathrm{TiO}_{2}$ nanopowder (Sigma-Aldrich, anatase, $<25 \mathrm{~nm}, 99.7 \%$ trace metals basis) and $\mathrm{ZnO}$ powder (Kemika, p.a., min. 99\%) were used as received.

\section{Preparation of $\mathrm{Au} / \mathrm{ZnOs}$}

Both gold-modified $\mathrm{ZnO}$ catalysts were prepared from pure $\mathrm{ZnO}$ powder by DC sputtering using a BAL-TEC SCD-005 (Bal-Tec) sputter coater. 500 $\mathrm{mg} \mathrm{ZnO}$ was measured in $5 \mathrm{~cm}$ diameter Petri-dish, dispersed in thin layer and sputtered with gold for $4 \times 15 \mathrm{~s}(\mathrm{Au} / \mathrm{ZnO} / 1)$ or $4 \times 90 \mathrm{~s}(\mathrm{Au} / \mathrm{ZnO} / 2)$. The watchglass covered dishes were intensively shaken between consecutive sputtering steps. The sputtering parameters were as follows: working time, $4 \times 15 \mathrm{~s}$ or $4 \times 90 \mathrm{~s}$; used current, $30 \mathrm{~mA}$; working distance, $50 \mathrm{~mm}$ ).

\section{Surface characterization}

Surface characterization of $\mathrm{Au} / \mathrm{ZnO} / 2$ was done with the aid of JSM6460LV electron microscope (Jeol, Japan) and INCAx-sight EDS detector (Oxford Instruments, United Kingdom). 


\section{Photodegradation}

Identical borosilicate glass beakers (IsoLab, 013.01.101) containing $10.00 \mathrm{~cm}^{3}$ of crystal violet solution with or without catalyst were subjected to natural solar irradiation (direct and diffuse) in consecutive sunny summer days. All catalyst-containing solutions were mixed during the experiments to minimize sedimentation. All experiments were done in duplicate. When the time of degradation was higher than the daily available insolation time (direct or diffuse), the samples were put into the dark before the next insolation session (next day).

\section{Visual decolorization monitoring}

During the preliminary comparative experiments (optimization) the decolorization of the samples was monitored visually. The time for the total decolorization $(t)$ was determined and mutually compared using a relative scale taking $100 \%$ for the most efficient system: relative efficiency $(\%)=$ $100 \times t_{\text {most eff. }} / t$. Kinetic investigation of the Au/ZnO/2 system was done by spectrophotometry according to procedure described below.

\section{Spectrophotometry}

Spectrophotometric investigation of the $\mathrm{Au} / \mathrm{ZnO} / 2$ system was performed on a PG Instruments T80+ UV-visible double-beam spectrophotometer (PG Instruments, United Kingdom) using quartz cuvettes with $1.00 \mathrm{~cm}$ path length. The samples for the analysis were filtered through appropriate membrane filters. The degradation of crystal violet was monitored at its three absorption maxima both in UV and visible range (249, 302 and $590 \mathrm{~nm})$. The initial absorbance was determined after the adsorption step (15 min in the dark).

\section{ACKNOWLEDGMENTS}

The financial support of the Ministry of Education, Science and Technological Development of the Republic of Serbia (Project No. ON172059) is gratefully acknowledged. Author would also like to thank Mr. Miloš Bokorov for his help in this research.

\section{REFERENCES}

1. C.A. Martínez-Huitle, E. Brillas, Applied Catalysis B: Environmental, 2009, 87, 105.

2. S.H.S. Chan, T.Y. Wu, J.C. Juan, C.Y. Teh, Journal of Chemical Technology and Biotechnology, 2011, 86, 1130.

3. S. Palit, Nature Environment and Pollution Technology, 2012, 11, 697. 
4. P.V. Kamat, Chemical Reviews, 1993, 93, 267.

5. G. Rothenberger, J. Moser, M. Grätzel, N. Serpone, D.K. Sharma, Journal of the American Chemical Society, 1985, 107, 8054.

6. P.V. Kamat, Journal of Physical Chemistry B, 2002, 106, 7729.

7. P.V. Kamat, Pure and Applied Chemistry, 2002, 74, 1693.

8. K. Rajeshwar, N.R. de Tacconi, C.R. Chenthamarakshan, Chemistry of Materials, 2001, 13, 2765.

9. A.A. Ashkarran, Applied Physics A, 2012, 107, 401.

10. P.-K. Chen, G.-J. Lee, S. Anandan, J.J. Wu, Materials Science and Engineering: $B, 2012,177,190$.

11. C. Chen, Y. Lu, H. He, K. Wu, Z. Ye, Applied Physics A, 2013, 110, 47.

12. J.W. Chiou, S.C. Ray, H.M. Tsai, C.W. Pao, F.Z. Chien, W.F. Pong, C.H. Tseng, J.J. Wu, M.-H. Tsai, C.-H. Chen, H.J. Lin, J.F. Lee, J.-H. Guo, Journal of Physical Chemistry C, 2011, 115, 2650.

13. R. Georgekutty, M.K. Seery, S.C. Pillai, Journal of Physical Chemistry C, 2008, 112, 13563.

14. C.A.K. Gouvêa, F. Wypych, S.G. Morales, N. Durán, P. Peralta-Zamora, Chemosphere, 2000, 40, 427.

15. J. Kim, K. Yong, Journal of Nanoparticle Research, 2012, 14, art. No. 1033.

16. Y. Lai, M. Meng, Y. Yu, Applied Catalysis B: Environmental, 2010, 100, 491.

17. P. Li, Z. Wei, T. Wu, Q. Peng, Y. Li, Journal of the American Chemical Society, 2011, 133, 5660 .

18. G. Sinha, L.E. Depero, I. Alessandri, ACS Applied Materials \& Interfaces, 2011, 3, 2557.

19. L. Sun, D. Shao, Z. Song, C. Shan, Z. Zhang, B. Li, D. Shen, Journal of Colloid and Interface Science, 2011, 363, 175.

20. T. Tan, Y. Li, Y. Liu, B. Wang, X. Song, E. Li, H. Wang, H. Yan, Materials Chemistry and Physics, 2008, 111, 305.

21. K. Thongsuriwong, P. Amornpitoksuk, S. Suwanboon, Journal of Sol-Gel Science and Technology, 2012, 62, 304.

22. J. Wang, X.M. Fan, Z.W. Zhou, K. Tian, Materials Science and Engineering: B, 2011, 176, 978.

23. J. Wang, Q. Hu, Z. Li, J. Guo, Y. Li, Materials Letters, 2012, 79, 277.

24. T.-J. Whang, M.-T. Hsieh, H.-H. Chen, Applied Surface Science, 2012, 258, 2796.

25. J.-J. Wu, C.-H. Tseng, Applied Catalysis B: Environmental, 2006, 66, 51.

26. F. Xiao, F. Wang, X. Fu, Y. Zheng, Journal of Materials Chemistry, 2012, 22, 2868.

27. J. Xie, Q. Wu, Materials Letters, 2010, 64, 389.

28. D. Zhang, F. Zeng, Research on Chemical Intermediates, 2010, 36, 1055.

29. Y. Chen, D. Zeng, K. Zhang, A. Lu, L. Wang, D.-L. Peng, Nanoscale, 2014, 6, 874.

30. Q. Huang, S. Liu, W. Wei, Q. Yan, C. Wu, RCS Advances, 2015, 5, 27075. 